\title{
Management of LBP at primary care level in South Africa: up to standards?
}

\author{
Mel E Major-Helsloot ${ }^{\S 1,2}$, Lynette C Crous $^{1}$, Karen Grimmer-Somers ${ }^{1,3}$, Quinette A Louw ${ }^{1}$
}

1. Physiotherapy division, Faculty of Medicine and Health Sciences, Stellenbosch University, PO Box 19063, Tygerberg, 7505 Cape Town, South Africa

2. European School of Physiotherapy, Amsterdam University of Applied Sciences/Hogeschool van Amsterdam, PO Box 2557, 1000 CN Amsterdam, the Netherlands

3. International Centre for Allied Health Evidence, University of South Australia, School of Health Sciences, GPO Box 2471, Adelaide SA 5001, Australia

\begin{abstract}
Background: Primary Health Care (PHC) is well suited for management of low back pain (LBP). Prevalence of (chronic) LBP is suspected to be high among visitors of the South African primary care centers, but currently no information exists on prevalence or guideline adherence.
\end{abstract}

Objectives: To establish if treatment received for LBP in public PHC in the Cape Town area compares with international evidence based guidelines.

Methods: Cluster randomization determined the 8 community health centres where the study took place. A measurement tool was developed and validated for this population. Descriptive analysis and logistic regression analytical techniques were applied.

Results: 489 participants (mean age: 44.8) were included in this study. Lifetime prevalence was $73.2 \%$ and 26.3\% suffered from chronic low back pain (CLBP) . Pain medication was the only form of treatment received by $90 \%$ of the sample. Interventions received seemed to be unrelated to type of LBP (acute, sub acute and chronic). Referral to physiotherapy, education and advice to stay active were rarely done. Participants expressed low satisfaction with treatment.

Conclusions: Current management of LBP at PHC level appears to be ineffective and not conform guidelines. Further South African research should focus on barriers as well as measures to be taken for implementation of LBP guidelines.

Keywords: Low back pain, management, guidelines, primary care, South Africa

DOI: http://dx.doi.org/10.4314/ahs.v14i3.28

\section{Introduction}

LBP is one of the most common persistent disorders managed at primary health care level [1]. Primary Health Care (PHC) provides an optimal platform for LBP management as this approach incorporates health promotion, prevention, as well as curative care [2]. PHC is people centered which creates the opportunity to build longstanding relationships between people and health care providers. The PHC approach is therefore well suited for persistent and costly conditions such as

\section{Corresponding author: \\ Mel E Major-Helsloot \\ Physiotherapy Division, \\ Faculty of Medicine and Health Sciences, Stellenbosch University, PO Box 19063, Tygerberg, 7505 Cape Town, South Africa \\ Email addresses: m.major@hva.nl / \\ major.dreams@hotmail.com}

LBP.

A recent review of evidence based LBP clinical guidelines, published over the past sixteen years, provides recommendations for LBP management at primary care level [3]. The review findings illustrate that there is consensus across all guidelines for the prescription of short acting analgesics and if necessary NSAID's on a time contingent basis rather than a pain contingent basis. In CLBP, pain medication, when deemed necessary, should be prescribed for short periods only to prevent adverse effects. All guidelines agree that reassurance, advice to stay active and early return to work have favorable outcomes in people with acute and sub acute LBP. Recently published updated guidelines for LBP in the Netherlands recommend that the clinician's decision on interventions offered, depend on the presence or absence of psychosocial factors. Three subgroups are specified; 'normal course of LBP', 'abnormal course with absence of psychosocial factors' and 'abnormal course in the presence of psychosocial factors'. Physiotherapy is indicated in all three subgroups, with the focus on education, graded 
activity and return to work. For the third subgroup an additional time-contingent exercise program (3-6 weeks) is recommended, the patient's progress to be closely monitored by the referring physician [4].

PHC is well established in the developed world and associated with decreased mortality rates. In the African region, PHC remains underdeveloped [2]. In developed economies such as the Netherlands, primary care involves $95 \%$ of all episodes of care [5]. Developed countries are generally well resourced to manage persistent disorders, such as LBP, at PHC level. In developing countries PHC systems are strained with consequences of the HIV/ AIDS pandemic and other infectious diseases such as tuberculosis. These 'twin epidemics' drain available resources as well as quality of care for other (persistent) health conditions and disorders [6].

In South Africa, public primary health care is organized through community health centers (CHCs) and clinics located in both urban and rural areas. In the Western Cape alone, nearly $70 \%$ of the population relies on the CHCs for their primary health needs. Prevalence of LBP among Africans compares well to developed countries and over the next few years the most marked increase in musculoskeletal disorders will occur in the developing world [7]. Management of LBP at primary health care must thus be delivered in accordance with evidence based guidelines to enhance effectiveness, prevent adverse effects and potentially reduce cost of care. The aim of this study was to describe the current management strategies for any type of LBP as perceived by the patients of public PHC facilities in the Cape Metropolitan region, South Africa.

\section{Methods}

A cross-sectional study was conducted to address the study aim. Ethical approval was obtained by the Committee for Human Research, Department of Research Development and Support, Stellenbosch University (Project nr: N08/05/148). Signed, informed consent was obtained from each subject in their native language.

The larger Cape Town area is divided into eight health districts; each consisting of 3-10 CHCs. Cluster randomization was performed to select one $\mathrm{CHC}$ per district. Facility managers of the CHCs were contacted by telephone to establish eligibility, and if found ineligible the next CHC on the list was selected. Data collection was done in three larger 24-hour CHCs (Kraaifontein, Michael Mapongwana, and Van Guard CHC) and five small day clinics (Lotus River, Macassar, Heideveld, St. Vincent, Inzame Zabantu).
All visitors attending the CHCs were included if they were $\geq 18$ years and literate as defined by UNESCO [8]. Patients attending the midwife obstetric unit were excluded.

Sample size calculation was based on the size of the population (across the daily visitors of the included CHCs) and a modest predicted point prevalence for LBP of $50 \%$. Modifying for the cluster effect sampling ascertained that 600 subjects were needed to provide 90\% statistical power for this study.

The Primary Health Low Back Pain Questionnaire (PHLBPQ) was developed and validated for this population. A patients' validation study was conducted among visitors of Elsies River CHC ( $=22)$. Comments on content, clarity, length and layout were gathered. An adjusted version of the draft questionnaire was reviewed by an expert panel of seven international researchers who published LBP epidemiological research. The final PHLBPQ included (parts of) the Dutch Musculoskeletal Questionnaire [9] for questions on pain prevalence and work related risk factors, the Kessler Psychological Distress Scale or K10 [10] and the Baecke Questionnaire for measurement of a person's habitual physical activity [11]. Questions on demographics, general health and medication use were included. The section on LBP was expanded with questions on treatment received and satisfaction with health care. The English version of the PHLBPQ was translated into Afrikaans and isiXhosa. The PHLBPQ was tested for reliability through a small test-retest study among a sample of 16 subjects, of which 12 completed the questionnaire on both occasions. Although the sample was small, reliability was established (Kappa of 1.00) for the questions on pain prevalence in the lower back, upper back, shoulder and feet.

Subjects were recruited by the first author in the clinician-, pharmacy- and general waiting area of the CHCs. Once eligibility was established and consent was obtained, subjects completed the questionnaire. Weight and height were measured with a calibrated scale and height measure to determine BMI (weight/length ${ }^{2}$ ). Each CHC was visited for one whole day and data collection took place over a two month period in 2009.

\section{Data analysis}

Data were analyzed using SAS 9.1. Descriptive statistics are reported as mean and standard deviations or percentages, as appropriate. Univariate logistic regression models were used to calculate odds ratios with 95\% confidence intervals to express the crude associations between individual exposures (considered 
in binary from) and LBP (also considered in binary form).

\section{Results}

Data was collected from 504 respondents. Fifteen were excluded for reasons of ineligibility, resulting in a study sample of $\mathrm{N}=489$. The mean age was $44.8(\mathrm{SD} \pm 13.95)$ and $76 \%$ of the sample were female.

The larger part of the sample $(67,5 \%, \mathrm{n}=330)$ were of very low socio-economic status ( $\leq \$ 100$ a month) with a subsample of $37,2 \%(n=182)$ living with an income below or around the poverty line [12]. Refer to Table 1 for sample characteristics.

Table 1 - Sample characteristics

\begin{tabular}{|c|c|c|}
\hline Variable & Number (\%) & Missing data \\
\hline Community Health Centre: & Respondents $(\mathrm{N}=489)$ : & \\
\hline Macassar & $51(10.5)$ & $\mathrm{N} / \mathrm{A}$ \\
\hline Kraaifontein & $70(14.3)$ & \\
\hline Van Guard & $68(13.9)$ & \\
\hline Lotus River & $44(9.0)$ & \\
\hline Michael Mapongwana & $93(19.0)$ & \\
\hline Inzame Zabantu & $60(12.3)$ & \\
\hline Belhar (St. Vincent's) & $50(10.2)$ & \\
\hline Heideveld & $53(10.8)$ & \\
\hline Female & $374(76.6)$ & 1 \\
\hline$<40$ yrs old & $178(36.5)$ & 26 \\
\hline $40-60$ yrs old & $217(44.5)$ & \\
\hline$>60$ yrs old & $68(13.9)$ & \\
\hline Black (African) descent & $233(47.8)$ & 13 \\
\hline Coloured (mixed) descent & $237(48.6)$ & \\
\hline Indian/Asian & $3(0.6)$ & \\
\hline White (Caucasian) & $3(0.6)$ & \\
\hline Primary school & $171(35.6)$ & 9 \\
\hline Grade 10 (standard 8) completed & $212(44.1)$ & \\
\hline High school diploma & $82(17.1)$ & \\
\hline College degree & $13(2.7)$ & \\
\hline University degree & $2(0.4)$ & \\
\hline Unemployed & $201(42.1)$ & 11 \\
\hline Employed & $119(24.9)$ & \\
\hline Housewife/retired/student & $150(31.4)$ & \\
\hline Monthly household income & & 30 \\
\hline$\leq \mathrm{US} \$ 50(\mathrm{ZAR} 500)$ & $182(39.6)$ & \\
\hline US\$ 50-100 (ZAR 500-1000) & $148(32.2)$ & \\
\hline US\$100-300 (ZAR 1000-3000) & $76(16.6)$ & \\
\hline US\$ 300-500 (ZAR 3000-5000) & $29(6.3)$ & \\
\hline$\geq$ US\$ $500($ ZAR 5000) & $24(5.2)$ & \\
\hline $\mathrm{BMI}<19$ & $17(3.5)$ & 2 \\
\hline BMI 19-25 & $130(26.7)$ & \\
\hline BMI 25-30 & $111(22.8)$ & \\
\hline BMI 30-40 & $193(39.6)$ & \\
\hline $\mathrm{BMI}>40$ & $36(7.4)$ & \\
\hline Participation in organized sports & & 49 \\
\hline No & $373(83)$ & \\
\hline $\begin{array}{l}\text { Yes } \\
\text { LBP classification longest period in }\end{array}$ & $77(17)$ & \\
\hline $\begin{array}{l}\text { LBP classification (longest period in } \\
\text { the past year) }(\mathrm{N}=357)\end{array}$ & & 132 \\
\hline Acute (1 day -1 month) & $211(59.1)$ & \\
\hline Sub acute (1 month- 3 months) & $52(14.5)$ & \\
\hline Chronic ( $\geq 3$ months) & $94(26.3)$ & \\
\hline
\end{tabular}


Prevalence of LBP and associated factors

Lifetime prevalence of LBP across the study sample was $73.2 \%(n=358)$. Further questions answered by a subsample of 357 respondents on length of the LBP period in the past year divided the LBP patients as follows: $59,1 \%(\mathrm{n}=211)$ had acute LBP ( $\leq 1$ month), $14,5 \%(\mathrm{n}=52)$ had sub acute LBP (1-3 months) and $26,3 \%$ ( $n=94)$ had chronic LBP ( $\geq 3$ months). Refer to
Table 1.

Factors associated with LBP were grouped into individual, physical and psychosocial risk factors. A strong association was found between LBP and a high score $(<27)$ on the K10 scale for psychosocial distress (OR 2.8 (95\% C.I.1.8-4.5). Refer to Table 2 for odds ratios and $95 \%$ confidence intervals as calculated for all relevant variables.

Table 2: Factors associated with LBP

\begin{tabular}{|l|l|}
\hline Variable & Odds Ratio $95 \%$ C.I.) \\
\hline Age $>44.85$ & $0.8(0.5-1.2)$ \\
\hline Female gender & $1.2(0.7-1.9)$ \\
\hline Being married & $0.9(0.6-1.5)$ \\
\hline Black (African) descent & $1.7(1.1-2.7)^{*}$ \\
\hline BMI $>29$ & $1.3(0.8-1.9)$ \\
\hline Fair or poor perceived general health & $2.4(1.5-3.7)^{*}$ \\
\hline $\begin{array}{l}\text { Health compared to 1 year ago } \\
\text { Setter } \\
\text { Wame }\end{array}$ & $0.4(0.3-0.8) \dagger$ \\
\hline Smokse & $0.3(0.2-0.6) \dagger$ \\
\hline Any type of co-morbidity & 1.0 \\
\hline Using any type of pain medication & $1.4(0.9-2.3)$ \\
\hline Physical fitness (cumulative score) & $1.8(1.2-.2 .9)^{*}$ \\
\hline K10 score $>$ 27 & $1.6(1.0-2.4)^{*}$ \\
\hline Chronic LBP and K10 scorett & $1.4(0.9-2.2)$ \\
\hline Treatment satisfaction & $2.8(1.8-4.5)^{*}$ \\
\hline Lifting, pushing, pulling, carrying $>20 \mathrm{~kg}$ & $2.3(1.2-4.2)^{*}$ \\
\hline Prolonged kneeling, squatting & $1.3(0.8-1.9)$ \\
\hline Driving & $3.3(1.2-8.5)^{*}$ \\
\hline Working with vibrating tools & $3.4(1.1-10.4)^{*}$ \\
\hline & $1.3(0.5-3.8)$ \\
\hline assocat & $2.1(0.8-6.0)$ \\
\hline
\end{tabular}

* Significant association between variable and LBP, OR $\geq$ than 1.0

† Significant protective factor for LBP

H Chronic LBP defined as: longest episode of LBP $>1$ month or $>5$ episodes of LBP in the past year

\section{Treatment received}

A sub sample of 302 participants answered 4 further questions on general medical treatment received for LBP. $90 \% \quad(\mathrm{n}=273)$ indicated that pain medication was the only form of treatment received. 33\% used two or more prescribed painkillers at the time of data collection. When compared between sub groups, pain medication was received by $93 \%(n=72)$ of the people with chronic LBP, $88.3 \%(n=43)$ of the people with sub acute LBP and $88.4 \%(n=147)$ of the people with acute LBP. Only $15.9 \%(n=48)$ of the sample with LBP received physiotherapy in the past year.

Data on physiotherapy visits for LBP during 
lifetime was collected on a larger sub sample of 396 participants. 30.8\% $(n=122)$ indicated they had received physiotherapy, as opposed to $69.2 \%(\mathrm{n}=274)$ to have never received physiotherapy. The physiotherapeutic interventions most commonly received were massage, exercises, and hot packs (Table 3).

433 participants $(88.5 \%)$ responded to the question if their $\mathrm{CHC}$ offered any education regarding predisposing factors of LBP. $76.7 \%(n=332)$ answered with either 'No' or 'I don't know' and 23.3\% (n=101) answered 'Yes'.

Participants who had indicated to be currently working
$(\mathrm{N}=169)$ were asked if they had ever been educated at work on LBP prevention. Nearly $85 \% \quad(n=144)$ responded to never have received any education or advice on ergonomics to prevent LBP.

\section{Satisfaction with treatment and consultation time $(\mathrm{n}=311)$}

Participants suffering from LBP were asked about their satisfaction with treatment and consultation time at the CHCs. 36.6\% $(n=114)$ indicated treatment had not helped at all, 48.2\% ( $\mathrm{n}=150)$ indicated treatment to have helped for a little while and 15.2\% $(n=47)$ responded that treatment had helped them a lot. Refer to Table 3.

Table 3 - Treatment received for LBP

\begin{tabular}{|c|c|}
\hline Treatment Received & $\mathrm{N}(\%)$ \\
\hline $\begin{array}{l}\text { Type of treatment received ( } \mathrm{n}=302) \\
\text { Pain medication } \\
\text { - Acute LBP (1 day - 1month) } \\
\text { - Sub acute LBP (1-3 months) } \\
\text { - Chronic LBP } \geq 3 \text { months }) \\
\text { Physiotherapy } \\
\text { Occupational therapy } \\
\text { Surgery }\end{array}$ & $\begin{array}{l}273(90) \\
147(88.4) \\
43(88.3) \\
72(93) \\
48(15.9) \\
6(2.0) \\
1(0.3)\end{array}$ \\
\hline $\begin{array}{l}\text { Type of pain medication * }(\mathrm{n}=273) \\
\text { Paracetamol } \\
\text { NSAIDs } \\
\text { Paracetamol + codeine } \\
\text { Amitriptyline/antidepressants } \\
\text { Cortizone injection } \\
\text { Grandpa's@ } * *\end{array}$ & $\begin{array}{l}160(58.6) \\
117(42.8) \\
75(27.4) \\
39(14.2) \\
84(20.7) \\
24(8.7)\end{array}$ \\
\hline $\begin{array}{l}\text { Satisfaction with treatment }(\mathrm{n}=311) \\
\text { Treatment did not help at all } \\
\text { Treatment helped for a little while } \\
\text { Treatment helped a lot }\end{array}$ & $\begin{array}{l}114(36.6) \\
150(48.2) \\
47(15.1)\end{array}$ \\
\hline $\begin{array}{l}\text { Satisfaction with consultation time }(\mathrm{n}=301) \\
\text { Clinician took enough time to answer my } \\
\text { questions } \\
\text { Not enough time to ask all my questions } \\
\text { No time to ask any of my questions }\end{array}$ & $\begin{array}{l}130(43.2) \\
80(26.6) \\
91(30.2)\end{array}$ \\
\hline $\begin{array}{l}\text { Type of physiotherapy treatment }(\mathrm{n}=122) \\
\text { Massage } \\
\text { Exercises } \\
\text { Hot packs } \\
\text { Advice and education } \\
\text { Electrotherapy } \\
\text { Manual therapy/mobilization } \\
\text { Dry needling/acupuncture } \\
\text { Other }\end{array}$ & $\begin{array}{l}64(48.8) \\
62(46.9) \\
56(42.2) \\
23(17.4) \\
21(15.9) \\
13(9.8) \\
3(2.2) \\
1(0.7)\end{array}$ \\
\hline
\end{tabular}

* More than one answer possible

** Over the counter medicine: working substance paracetamol, caffeine, aspirin 


\section{Discussion}

This is the first South African study to report on management strategies for any type of LBP at primary health care level. Despite a high lifetime prevalence among the study sample our data show that the most common form of management is the prescription of pain medication in both acute, sub acute and chronic LBP. Physiotherapy referral is rare, and when provided the main interventions offered, such as hot packs and massage, are passive treatment strategies which lack evidence of effectiveness. Clinicians do not offer advice to stay active or education, in any phase of LBP. Louw et al (2007) confirm in a systematic review that the prescription of pain medication is the most common form of treatment offered to LBP patients on the African continent [7]. Prescription of analgesics and NSAIDs are recommended in acute LBP. However evidence for the effect of pain medication decreases in strength as acute LBP transitions into chronic LBP $[3,13,14]$. Prescription of pain medication on a regular basis creates patient dependence and prolonged use could lead to physical adverse effects such as gastrointestinal complaints, drowsiness, and headaches [15] which in turn can result in further long-term morbidity and associated increases in cost of care [16]. Pharmaceutical costs take up about one third of the total budget of the CHCs [17]. Compared to the cost of alternative, evidence based treatment prescribing medication might seem a cheaper option, but a recent systematic review on the cost effectiveness of evidence based interventions for LBP states the exact opposite. No evidence was found on cost effectiveness of medication in patients with sub acute and chronic LBP. Most of the included studies found cost effectiveness for multidisciplinary rehabilitation including physiotherapeutic interventions [18].

The findings of this study illustrate that current LBP management strategies offered at the public PHC facilities in South Africa are not in alignment with published evidence based guidelines. Our study sample was representative of South Africans in lower socioeconomic situations, as $83 \%$ of the general population is uninsured and visits the CHCs for their primary health needs [19]. A quarter of our sample with LBP had chronic LBP. This study found an association between psychosocial distress and CLBP. However, our sample did not receive evidence based interventions such as graded activity or multidisciplinary interventions recommended for patients suffering from CLBP and psychosocial distress [4].
International guidelines recommend advice and education for both acute and chronic LBP. The results of this study show that the majority of clients with LBP did not receive education to re-assure and assist them with self management strategies. An explanation could be that clinicians at the CHCs in the Cape Metropolitan district suffer from a high workload. Medical doctors at the CHCs must perform a minimum of 30 patient consultations per day and a professional nurse about 28 patient consultations per day, but it is likely that the daily workload is much higher considering the statistics on daily visitors [20]. Previous studies recognize that a high workload stands in the way of adherence to guidelines [21, 22]. In the setting of the South African CHCs physiotherapists should be involved earlier, after the first consultation, to assist the clinicians in a more extensive screening of the LBP patients, in order to decide on appropriate interventions or further referral.

Non adherence to LBP guidelines is not restricted to PHC facilities in the developing world. Scott et al (2010) conducted a systematic review on 14 studies published in Europe, Canada and the USA with the aim to identify the so called 'know-do' gap in primary care setting [23]. The know-do gap refers to the discrepancy between management advised by the guideline and management executed in clinical practice [23, 24]. Evidence of the existence of this know-do gap among physicians and physiotherapists could be seen in the choice of treatments strategies. Education, advice and exercise rehabilitation, were not used enough and treatments which were found to be ineffective, such as TENS, ultrasound and traction, were overused [23]. A recent Norwegian study reported on changes in LBP management among physicians in the last 10 years. Management seems to be largely unchanged, except for a significant decrease in physiotherapy referrals [25]. A Spanish prospective study on management of LBP among physicians describes prescription of pain medication in $78-91 \%$ of the cases (both acute, sub acute and chronic LBP patients) and physiotherapy referral only in $25 \%$ of the consultations [26].

The mismatch between current management and recommendation of LBP guidelines yields ineffective approaches, which may be indicative by the high prevalence $(26,3 \%)$ of participants with CLBP. This study shows that participants with acute and sub acute LBP also did not receive evidence based interventions, so the number of patients with chronic LBP at PHC level in South Africa is likely to grow. Dissatisfaction 
with treatment as highlighted in this study is a concern. Possible explanations for the dissatisfaction with care could be the high turnover of staff and the short consultation time as a result of the high workload. Both these factors stand in the way of building a healthy professional-patient relationship. Sans-Corrales et al (2008) come to similar conclusions regarding patient satisfaction in family medicine [22]. Inefficient management systems at primary care will lead to high levels of recurring visits and an even greater workload of the medical staff.

Efforts to improve quality of care through the implementation of evidence based medicine has mainly focused on hospital and specialist care in high- and middle income countries [2]. Low income countries, such as South Africa, are faced with large medical issues such as HIV/AIDS, TB and malaria and therefore might not prioritize the implementation of LBP guidelines. A recent systematic review [27] on the effectiveness of prevention in primary care in Switzerland indicates barriers from general practitioner's (GP) perspective and patient perspective. High workload and lack of time, lack of knowledge and own disbeliefs, were barriers most frequently mentioned by GP's. Patients indicated the lack of GPs' engagement or encouragement, lack of motivation and own disbeliefs as barriers for success of the treatment.

Limited health literacy could be another possible explanation for patients' non-involvement in management of their LBP, which in turn can lead to the feeling of disempowerment especially in consultations with healthcare workers who might be more paternalistic in their approach [28].

Low socio-economic status and associated psychosocial distress could explain why the visitors of the CHCs do not seem to prioritize treatment of their LBP. Jelsma et al (2008) conducted a study on health related quality of life (HRQoL) among isi-Xhosa speaking inhabitants of informal settlements in the Cape Town area, a population greatly similar to that of our own study. The aim was to portray the HRQoL-items most valued by this population. Where food availability came first and owning a brick house second, having no bodily pain was listed on the $40^{\text {th }}$ place on the list of most valued items [29]. The results of the study imply that when basic needs are not provided for, seeking treatment for physical pain is not a priority.

Guidelines for LBP and evidence based health systems should be developed and implemented in PHC facilities in developing countries such as South Africa. A more thorough screening for yellow flags should be done at first consultation, after which the LBP patient, according to the phase of recovery he is in, can be appropriately referred. CHC staff should receive training to improve their knowledge of LBP and risk factors for chronicity [24]. Within the current shift taking place in South African CHCs towards a patient- centered perspective, attention should be given to improving patients' health literacy. This can be accomplished by offering educational programs to groups of patients with LBP in a multidisciplinary setting. PHC is the optimal approach to conduct and implement research on diagnostics and treatment of any type of condition [5,30]. Staff should be primarily involved in the development and implementation of guidelines, based on their unique expertise.

Limitations to this study are the cross-sectional design as well as the relatively small study sample, with its particular demographics which needs to be taken into consideration when generalizing the findings. The measurement tool requires further psychometric testing, especially the section on treatment strategies and satisfaction with treatment. An adjusted measurement tool should allow for obtaining separate data on the management of the acute, sub acute and chronic LBP patients. The study includes information only on the patients' perception of their received treatment and lacks the perspective of the clinician. The primary health care setting and population are likely to have created bias with respect to the findings related to prevalence of LBP.

\section{Conclusion}

This cross-sectional study highlights the current nonevidence based approaches and lack of well developed health systems to manage acute and chronic LBP at primary care level in South Africa. Ineffective management strategies for LBP may lead to increased costs, increased cases of chronicity and disability, lack of motivation among health workers as well as lack of patients' compliance. Further South African research should focus on barriers for implementation of LBP guidelines as well as the type of intervention needed in order to successfully implement evidence based strategies for LBP at primary care level.

\section{Competing interests}

Mel Major-Helsloot was employed as physiotherapist at Elsies River Community Health Centre during the 
period July 2007- April 2009 and received a salary during this period. Elsies River CHC and its visitors have NOT participated in the cross sectional study; therefore there are no competing interests.

The other authors declare that they have no competing interests.

\section{Authors' contributions}

$\mathrm{MMH}$ was the main researcher; wrote the protocol for the study, performed the data collection and drafted the manuscript,. LC was co-investigator, KG assisted with data analysis and drafting of the paper, QL was co-investigator and assisted in drafting the paper.

\section{Acknowledgements}

We thank the faculty of Health Sciences, Stellenbosch University for providing funding for the costs of this research. We thank the management of the following Community Health Centres for facilitating data collection at their institution: Kraaifontein CHC, Michael Mapongwana CHC, Lotusriver CHC, Van Guard CHC, Macassar CHC, Heideveld CHC, St. Vincent CHC, and Inzame Zabantu CHC.

\section{References}

1. Henschke N, Maher CG, Refshauge KM: Screening for malignancy in low back pain patients: a systematic review. Eur Spine J 2007, 16: 1673-1679.

2. World Health Organization: The World Health Report 2008: Primary Health Care - Now more than ever. WHO, 2008, [link: http://www.who.int/whr/2008/en/ ]

3. Koes BW, Van Tulder M, Lin C-WC, Macedo LG, McAuley J, Maher C: An updated overview of clinical guidelines for the management of non-specific low back pain in primary care. Eur Spine J 2010, 19:2075-2094.

4. Staal JB, Hendriks EJM, Heijmans M, Kiers H, Lutgers-Boomsma AM, Rutten G, et al: KNGF richtlijn lage rugpijn, praktijkrichtlijn [Dutch] Amersfoort 2013 5. Van Weel C, Schers H, Timmermans A: Health care in the Netherlands. J Am Board Fam Med 2012, 25:S1217.

6. Bateman E, Feldman C, Mash R, Fairall L, English R, Jithoo A: Systems for the management of respiratory disease in primary care - an international series: South Africa. Prim Care Resp J 2009, 18 (2): 69-75.

7. Louw QL, Morris LD, Grimmer-Somers K: The prevalence of low back pain in Africa: a systematic review. BMC Musculoskeletal disorders 2007, doi:10.1186/14712474-8-105

8. Unesco: Education for all Global Monitoring Report.

\section{6: 27-35. [link www.unesco.org]}

9. Hildebrandt VH, Bongers PM, Van Dijk FJ, Kemper HC, and Dul J: Dutch Musculoskeletal Questionnaire: description and basic qualities. Ergonomics 2001, 44 (12):1038-1055.

10. Kessler RC, Andrews G, Colpe LJ, Hiripi E, Mroczek DK, Normand S-LT, et al: Short screening scales to monitor population prevalences and trends in non-specific psychological distress. Psychological Medicine 2002, 32:959-976.

11. Baecke JAH, Buruma J, Frijters ER: (1982). A short questionnaire for the measurement of habitual physical activity in epidemiological studies. American Journal of Clinical Nutritrion 1982, 36:936-942.

12. World Bank. Poverty [Internet]. 2013 November [cited 2013 Nov 21] Available from: http://data.worldbank. org/topic/poverty

13. Rossignol M, Arsenault B, Dionne C, Poitras S, Tousignant M, Truchon M, et al: Clinic on Low Back Pain in Interdisciplinary Practice (CLIP) guidelines. Montréal: Direction de santé publique, Agence de la santé et des services sociaux de Montréal, 2007.

14. Airaksinen O, Hildebrandt J, Mannion AF, Ursin H, Brox JI, Klaber-Moffett J, et al: European Guidelines for the management of chronic non specific low back pain. 2004, Amended version June 14 2005.

15. Mens JMA: The use of medication in low back pain. Best Practice \& Research Clin Rheumatology 2005, 19(4):609621.

16. Fritz JM, Brennan GP, Hunter SJ, Magel JS: Initial management decisions after a new consultation for low back pain: implications of the usage of physical therapy for subsequent health care costs and utilization. Arch Phys Med 2013, http://dx.doi.org/10.1016/j. apmr.2013.01.008

17. Department of Health Western Cape, Metropole District Health Services: Annual Report 2003-2004, Cape Town: 2004.

18. Lin C-WC, Haas M, Maher CG, Machado LAC, Van Tulder MW: Cost effectiveness of guideline endorsed treatments for low back pain: a systematic review. Eur Spine J 2011, 20:1024-1038

19. Statistics South Africa (2009). General Household Survey, statistical release P0318, embargoed until 6/05/2010 [online] www.statssa.gov.za

20. Western Cape Department of Health: Comprehensive service plan for the implementation of healthcare 2010. 2007: http://www.capegateway.gov.za/eng/your_ gov $/ 305$

21. Breen AC, Van Tulder MW, Koes BW, Jensen I, Reardon R, Bronfort G: Mono-disciplinary or multidis- 
ciplinary back pain guidelines? How can we achieve a common message in primary care? Eur Spine J 2006, 15: 641-647

22. Sans-Corrales M, Pujol-Rebeira E, Gené-Badia J, Pasarín-Rua MI, Iglesias-Peréz B, Casajuano-Brunet J: Family medicine attributes related to satisfaction, health and costs. Fam Pract 2008, 23(3):308-316

23. Scott NA, Moga C, Harstall C: Managing low back pain in the primary care setting: the know-do gap. Pain Res Manage 2010, 14(6):392-400

24. Slater H, Davies SJ, Parsons R, Quintner JL, Schug SA: A policy-into-practice intervention to increase the uptake of evidence-based management of low back pain in primary care: a prospective cohort study. PLoS ONE 2012, 7(5): e38037.

25. Werner EL, Ihlebæk C: Primary doctor's management of low back pain patients - ten years after. Tidsskr Nor Legeforen 2012, 21(132):2388-2390

26. Kovacs FM, Fernández C, Cordero A, Muriel A, González-Luján L, Gil de Real MT and the Spanish
Back Pain Research Network: Non-specific low back pain in primary care in the Spanish National Health Service: a prospective study on clinical outcomes and determinants of management. BMC Health Services Research 2006, 6:57

27. Eisner D, Zoller M, Rosemann T, Huber CA, Badertscher N, Tandjung R: Screening and prevention in Swiss primary care: a systematic review. Int J Gen Med 2011, 4:853-870

28. Edwards M, Wood F, Davies M, Edwards A: The development of health literacy in patients with a longterm health condition: the health literacy pathway model. BMC Public Health 2012, 12:130.

29. Jelsma J, Mkoka S, Amosun SL: Health related quality of life (HRQoL) most valued by urban isi-Xhosa speaking people. Quality of Life Research 2008, 17:137145

30. Beasley JW, Starfield B, Van Weel C, Rosser WW, Haq CL: Global health and primary care research. J Am Board Fam Med 2007, 20:518-526. 